\title{
José Joaquim da Rocha e a experiência do constitucionalismo na historiografia da Independência do Brasil no século XIX*
}

\author{
José Joaquim da Rocha and the experience of constitutionalism in the \\ historiography of the Brazilian Independence in the $19^{\text {th }}$ century
}

\author{
Luana Melo e Silva \\ luahistoria@gmail.com \\ Pós-doutoranda em História \\ Universidade Federal de Ouro Preto \\ Rua C, 25, Condomínio Residencial Padre Viegas \\ 35420-000 - Mariana - MG \\ Brasil
}

\section{Resumo}

Neste artigo, examinamos algumas obras produzidas ao longo do século XIX sobre a Independência do Brasil. Disputas relativas a distintos projetos nacionais e formas de escrever a história atravessavam essas narrativas. Concorriam, entre outras, duas versões principais do "evento" Independência: a de um processo conduzido pelo Estado corporificado pela monarquia bragantina e a de uma nação que emergira do "patriotismo" e do envolvimento direto da sociedade civil no processo. Acompanhamos nas obras de José da Silva Lisboa, Francisco Adolfo de Varnhagen, Alexandre José de Mello Morais e autores ligados ao Instituto Histórico Geográfico Brasileiro (IHGB) o cotidiano, os eventos principais e personagens como José Joaquim da Rocha, laureado em certas narrativas como "o primeiro motor da independência". Acreditamos que a versão apresentada pela historiografia que viria a se tornar hegemônica, a de um processo conduzido pela dinastia bragantina, suprimiu a ação da sociedade civil, parte importante da experiência constitucional e de uma tradição historiográfica que resistiu a essa versão preponderante.

\section{Palavras-chave}

Historiografia brasileira; Independência do Brasil; José Joaquim da Rocha.

\begin{abstract}
In this article, we examine some works produced throughout the $19^{\text {th }}$ century on the independence of Brazil. Disputes concerning different national projects and ways of writing history mark these narratives. Among others, two main versions of the "Independence" event prevailed: A process leaded by the state, embodied by the Bragantine monarchy, on the other hand, a nation that emerged from the "patriotism" and the direct implication of the civil society. In the works of José da Silva Lisboa, Francisco Adolfo de Varnhagen, Alexandre José de Mello Morais, and other authors linked to the Instituto Histórico Geográfico Brasileiro (IHGB), whe analyze the everyday life, the main events and figures, such as José Joaquim da Rocha - honored in certain narratives as "the first engine of the independence". We believe that the version presented by the historiography that would become hegemonic - of a process led by the Bragantine dynasty - suppressed civil society actions, an important part of the constitutional experience and of a historiographical tradition that resisted this prevalent version.
\end{abstract}

Keywords

Brazilian historiography; Brazil's Independence; José Joaquim da Rocha.

Recebido em: 7/3/2017

Aprovado em: 13/12/2017

\footnotetext{
* Este artigo é resultado de minha pesquisa de doutorado, financiada durante quatro anos pela Coordenação de Aperfeiçoamento de Pessoal de Nível Superior (Capes), que também financiou o estágio de doutorado sanduíche no exterior.
} 
Boa parte da historiografia brasileira que trata dos processos de independência, das revoluções liberais e constitucionalistas e da formação dos Estados nacionais na primeira metade do século XIX apresenta como problematização recorrente a ausência de elementos tipicamente liberais nos processos ocorridos na Espanha, em Portugal e nas suas antigas possessões atlânticas. Ao observar os referidos eventos na América portuguesa, tal historiografia destaca a forte influência do catolicismo, da economia escravista e a condução da monarquia nos processos de independência política. Haveria, portanto, limitações para o desenvolvimento do liberalismo/constitucionalismo nesse território, de maneira que tais ideologias não poderiam ser mais que uma distorção ou adaptação precária do liberalismo britânico, francês ou norteamericano à nossa supostamente incompleta sociedade colonial.

Acreditamos que as bases para esse tipo de interpretação foram lançadas em obras escritas ao longo do século XIX no Brasil, como as de José da Silva Lisboa (1756-1835), João Manuel Pereira da Silva (1817-1898), Francisco Adolfo de Varnhagen (1816-1878) e, ainda, no tipo de história elaborada no interior do Instituto Histórico Geográfico Brasileiro (IHGB) a partir de sua fundação em 1838. Essas obras tinham uma missão clara de produzir uma história-memória que valorizasse o papel do Estado, da monarquia e da herança civilizatória portuguesa, ainda que apresentassem algumas sutilezas interpretativas que demonstraremos ao longo deste artigo. De maneira geral, colocariam a casa de Bragança sempre no centro dos acontecimentos, relegando à sociedade civil um papel inexpressivo ou mesmo indesejável em todo o processo.

Essa historiografia conviveu com outro viés que Marco Morel (2007) denomina o "rubro veio", que contaria em suas fileiras como o revolucionário de 1817 Francisco Muniz Tavares (Pernambuco, 1793-1876), entre outros representantes. O tipo de narrativa que caracterizava essa segunda corrente (constituída entre os anos de 1820 e 1840, a princípio pela imprensa) transitava entre a memória e a história. O rubro veio historiográfico "nutriu-se preferencialmente de formulações próximas às dos liberais Exaltados" (MOREL 2007, p. 196), enquanto que a obra de autores como Gonçalves de Magalhães, ou seja, ligados ao IHGB e ao projeto do Estado monárquico, "alimentou-se de Moderados e Caramurus" (GUIMARÃES 1995).

No campo dos estudos historiográficos, Valdei Araujo defende a ideia de que essas distintas formas narrativas evidenciam a existência de diferentes regimes de autonomia do discurso histórico naquele contexto. Exemplo disso são as narrativas de Alexandre José de Mello Moraes (1816-1882), que se aproximavam das crônicas da política feita nas ruas, nos clubes, nos cafés, na maçonaria. Com o tipo de história que produzia, Mello Moraes, que concebia a escrita como ação política direta, visava certamente um público mais amplo. Baseada na prática da compilação (ARAUJO 2015), apresentava as seguintes características: fusão entre documento e relato, demandas locais/regionais de identidade e justificação política, resistência à erudição em padrão disciplinar, presença de linguagem sentimental, preocupação com a síntese e oferta de uma versão menos documentada, apoio do sistema de subscrição e editorial. 
Interessam-nos algumas características narrativas dessa segunda tendência, como a valorização dos personagens, que tinham nomes e feições, ocupavam diversas posições da hierarquia social e eram colocados no centro dos acontecimentos, num momento em que a memória candente do período revolucionário francês era apagada pela produção intelectual do contexto da Restauração (MOREL 2007). Enquanto de Mello Moraes colocava as ruas, personagens como José Joaquim da Rocha e a sociedade civil no panteão nacional, na historiografia produzida no âmbito do IHGB, preocupada em abafar qualquer tendência revolucionária de suas narrativas, só havia espaço para um grande herói nacional: D. Pedro I, herdeiro legítimo do trono e, ainda assim, um monarca "constitucional". ${ }^{1}$

Orientamo-nos pelo conceito de esfera pública moderna, como reunião de "pessoas privadas". Estas pessoas privadas seriam, na descrição de Habermas (2003), a sociedade civil (setor de trocas e mercadorias, do trabalho social) e espaço íntimo da pequena família, que emergem em um contexto em que as coisas do Estado não são mais prerrogativa do rei. Para o caso brasileiro observamos estas categorias sendo utilizadas por autores como Marco Morel (2005), que observa a emergência de uma esfera pública de debate político em lugares de sociabilidade como os cafés e outros espaços urbanos no Rio de Janeiro imperial.

Acompanhamos, dessa maneira, as narrativas historiográficas sobre a Independência do Brasil, identificando o espaço dedicado àquilo que chamamos sociedade civil e a seus representantes, personagens como José Joaquim da Rocha e seu grupo.

José Joaquim da Rocha foi um órfão exposto à casa de proeminente família de Mariana, na província de Minas Gerais. Tornou-se advogado prático e, depois, capitão-mor. Em 1808 se mudou com a família para a Corte, onde passou a integrar o círculo de importantes figuras do cenário político como José Bonifácio de Andrada e Silva, Antônio de Menezes Vasconcelos de Drummond, Joaquim Gonçalves Ledo, Januário da Cunha Barbosa e outros, atuando especialmente nas ruas e fazendo articulações políticas em favor da Independência do Brasil. Àquela época, era conhecido por seus contemporâneos (como o general Jorge Avilez) como o "célebre rábula Rocha", figura ligada à agitação das ruas, em ação dita revolucionária. Já para a historiografia produzida dentro do regime disciplinar (ARAUJO 2015) aparece como o benemérito da Pátria, o conselheiro Rocha, sócio honorário do IHGB.

É nessas diferentes formas de narrar a história da Independência do Brasil e apresentar seus atores que se enquadram as disputas entre duas fontes distintas de legitimidade do evento: a nação que emergia do patriotismo da sociedade civil ou da ação generosa da dinastia de Bragança (MOREL 2007). Acreditamos que a preponderância desta versão produzida dentro do cânone historiográfico disciplinar em construção sobre aquela produzida por autores 
como de Mello Moraes, Muniz Tavares, Felício dos Santos, João Francisco Lisboa colaborou para que parte importante da experiência constitucional do período da Independência fosse suprimida dos registros historiográficos.

\section{Mello Morais e a Independência feita nas ruas}

Alexandre José de Mello Moraes (1816-1882) nasceu em Alagoas e faleceu no Rio de Janeiro. Era médico, atuou como parlamentar e jornalista, escreveu biografias de figuras ilustres, crônicas da história do Brasil e ficaria conhecido especialmente por seu trabalho de reunir fontes e documentos históricos importantes.

De acordo com Marco Morel, este autor teria ficado "estigmatizado" "por não ter escrito, como almejava, uma história geral do Brasil, que pretendia contrapor-se às obras do mesmo gênero publicadas por Varnhagen e Pereira da Silva" (MOREL 2007, p. 200). Para José Honório Rodrigues, a história produzida por Moraes não era "construção baseada em documentos, mas transcrição". O problema com esse tipo de história seria, para Rodrigues (apud SANTOS 2013, p. 46), "o trato da matéria história" e sua concepção sobre o uso de documentos. De acordo com Pedro Afonso dos Santos (2013), Moraes seria acusado de plágio ao enviar alguns trabalhos biográficos ao IHGB.

A obra História do Brasil-reino e Brasil-império, de autoria de Alexandre José de Mello Moraes, pode ser filiada ao regime de autonomia compilatório sistematizado por Araujo (2015). Já em sua primeira página, encontra-se o anúncio das outras diversas obras do autor e o preço de cada uma delas. As biografias de Diogo Antônio Feijó e de Manoel Joaquim de Menezes custavam $1 \$ 000$ réis. A lista é extensa e abrange temas que vão da Medicina, apontamentos biográficos à história da Inglaterra e memórias de guerras. Logo abaixo do anúncio "obras do Dr. Mello Moraes", segue o informe: "que se acham à venda no seu consultório e nas diferentes lojas de livros do Rio de Janeiro".

De Mello Moraes, que escrevia sobre uma infinidade de assuntos, parecia identificar o crescente interesse por História e perceber a emergência de um mercado importante. Passou a publicar muitas obras de História que pareciam voltadas para um público mais amplo. O Tomo I da obra História do Brasil-reino e Brasil-império se divide em textos que informam o leitor sobre os eventos, os atores, os acontecimentos e o cotidiano do período da Independência do Brasil. Moraes produz uma narrativa densa e minuciosa de um momento que se desenrolou ao longo de três anos $(1820,1821,1822)$. Os pontos de partida das obras de Moraes e Varnhagen são distintos e dão a tônica das diferentes perspectivas dos autores. Moraes inicia sua narrativa com uma análise do evento da Inconfidência Mineira, que ele chama "constituição mineira de 1789". Ele valoriza o papel das sociedades secretas e dos indivíduos que dela participaram. Minas Gerais, em 1789, seria uma das primeiras manifestações da emergência de uma sociedade civil composta por indivíduos que expressaram seus "desejos de independência". Já a narrativa de Varnhagen começa com a chegada da corte ao Brasil, valorizando a importância do papel da dinastia bragantina na construção do império que daí surgiria. 
Alexandre José de Mello Moraes usa abundantemente o termo "revolução" com a conotação positiva de movimento de mudança e contestação legítima do status quo por parte de indivíduos/cidadãos virtuosos e capazes de conduzir a nação ao seu melhor caminho: ${ }^{2}$ a Revolução de Portugal de agosto de 1820 , a Revolução do Pará de janeiro de 1821, a Revolução de 26 de fevereiro de 1821 no Rio de Janeiro... O termo "revolução", evitado no contexto da restauração por alguns autores, adquiria outros sentidos em narrativas como a de Moraes. Para a história "não oficial" e popularizada na segunda metade do século XIX, o termo "revolução" adquiria conotação positiva. Seria um processo legítimo, conduzido por aqueles que deveriam estar à frente dos negócios do Estado no lugar dos atuais ministros e do poder executivo de maneira geral. Exemplo desses homens que deveriam estar no poder seria Vasconcellos de Drummond, membro do grupo que esteve à frente do processo de Independência do Brasil e a quem a obra de Mello Moraes é dedicada. Na dedicatória do livro, Moraes critica largamente os novos contornos do Estado e o funcionamento do Congresso. $\mathrm{O}$ país teria virado uma "grande fazenda do executivo", que não "respeita o pacto social da nação, e o povo, escravo da gleba" (MORAES 1871, p. 8).

Em sua descrição do período da Independência, na cronologia e entre os principais atores e eventos estarão sempre em primeiro plano as sociedades secretas e os indivíduos, que, na narrativa de Moraes, adquirem nomes, feições, temperamento. $O$ autor destaca, por exemplo, eventos como a fundação da chamada loja Distintiva, em Praia Grande, hoje Niterói. O mineiro, capitão-mor José Joaquim da Rocha, seria um de seus fundadores e a loja teria funcionado por muito pouco tempo, sendo fechada por D. João VI. Seriam membros da casa figuras como Antônio Carlos Ribeiro de Andrada, o padre Belchior Pinheiro de Oliveira, Luiz Pereira da Nobrega, o citado Vasconcellos de Drummond, entre outros. A loja teria ficado bastante conhecida a ponto de ser denunciada "às autoridades". José Joaquim da Rocha teria sido interrogado pelo intendente-geral Paulo Fernandes Vianna, que ordenara seu fechamento em nome do príncipe regente. Outros relatos de contemporâneos dariam conta de que Rocha, em 1815, passaria a fazer parte da loja Comércio e Artes, do grupo de Joaquim Gonçalves Ledo e do padre Januário Barbosa. Esta loja também teria sido fechada por D. Joao VI em 1821. De Moraes relata que, nesse mesmo ano, o capitãomor mineiro José Joaquim da Rocha transformaria sua casa em um clube que ficaria conhecido como "clube da resistência" ou "clube da independência", do qual faria parte o mesmo já citado grupo, tendo sido frequentado, inclusive, por Dom Pedro. Há uma parte do texto dedicado às "reuniões em casa do capitãomor Rocha na rua da Ajuda n. 64 e no convento, para a revolução do Brasil e resposta do sr. D. Pedro" (MORAES 1871, p.80). A narrativa de Mello Morais fornece detalhes do cotidiano do grupo e das articulações que Rocha encabeçaria contra os "decretos recolonizadores" das cortes de Lisboa e pela permanência do príncipe. O grupo atuaria no sentido de evitar o regresso do regente a Portugal,

${ }^{2}$ Não pretendemos desenvolver aqui um debate sobre o conceito. Sobre o assunto, ver: Pimenta (2014) e Neves (2007). 
a supressão dos tribunais, entre outras medidas consideradas "recolonizadoras". O autor se ocupa em reproduzir na obra as atas das reuniões/sessões e, em nota, acusa João Manoel Pereira da Silva "na sua obra Fundação do Império" de dar "este escrito como trabalho seu, copiando-o ipsis verbis - no tomo 7 da dita sua obra sem mencionar o meu Brasil Histórico" (MORAES 1871, p. 90).

Mello Moraes descreve as articulações encabeçadas por José Joaquim da Rocha, valorizando a ação desse personagem. Naquele contexto teria trocado correspondência com políticos de São Paulo e do interior de Minas Gerais; teria escrito a José Bonifácio e Martin Francisco Ribeiro de Andrada pedindo a adesão da Junta Governativa da província em favor do clube da Rua da Ajuda. A intenção do grupo representado por Rocha seria angariar a adesão de figuras importantes no interior de Minas Gerais. Rocha solicitava, também, que fosse redigida uma representação em favor da permanência de Dom Pedro no Brasil. De acordo com a narrativa de Moraes, àquela altura, o próprio D. Pedro sugerira que a reunião para redação dessa representação acontecesse na cela do frei Sampaio, no convento de Santo Antônio, já que o general Jorge Avilez e sua divisão auxiliadora já observava de perto as articulações do grupo.

O episódio, que passaria à história como o dia do "Fico", foi, sem dúvida, a atuação mais expressiva de personagens como José Joaquim da Rocha e viria a consagrá-lo como o "motor da Independência", com uma determinada historiografia inserindo-o no rol dos nomes dignos de nota. Historiadores viriam a considerar o Fico como o evento que precipitou a Independência. A qualidade de hábil articulador, em ação dita "patriótica", ou seja, em favor da "causa do Brasil", num momento em que essas características seriam associadas à ação constitucionalista, seriam fatores decisivos na construção da memória de grande benemérito de Rocha.

A atuação do Clube da Resistência é constantemente ligada à ação de afixar cartazes pelas esquinas da cidade do Rio de Janeiro, convocando o povo a "levantar-se" em apoio ao príncipe. Tais ações foram associadas à ideia de civismo nas memórias e crônicas de Mello Morais. De acordo com o autor, sua narrativa se baseava em documentos e nos depoimentos orais de contemporâneos como Cônego Geraldo Leite Bastos, Inocêncio Maciel da Rocha (filho de José Joaquim da Rocha), José da Silva Lisboa, Manoel Joaquim de Menezes, Luís Alves de Lima e Silva (o Duque de Caxias), e outros. Estes testemunhos davam conta de que o clube da Rua da Ajuda passara a colher as assinaturas para uma representação em apoio a $\mathrm{D}$. Pedro. Rocha teria sido autor de um anúncio convocando a população a comparecer à sua residência a fim de ler e assinar a representação. O general Jorge Avilez teria naquele dia enviado suas tropas à sua casa para "prender, de preferência, o célebre Rábula Rocha" (PARTICIPAÇÃO E DOCUMENTOS 1822, p. 10).

O que podemos atestar de verossímil na narrativa de Moraes sobre o Clube da Rua da Ajuda era que, de fato, o grupo estaria organizado em ações civis. Januário da Cunha Barbosa e Joaquim Gonçalves Ledo atuavam junto à imprensa, Joaquim José de Almeida, irmão de Rocha, nos quartéis, enquanto o próprio Rocha e Vasconcellos de Drummond, nas ruas e nos "centros comerciais". 
Há uma sincronia entre as ideias divulgadas em jornais como o Revérbero Constitucional Fluminense, de Joaquim Gonçalves Ledo e José Clemente Pereira, e as ações do grupo. Nos relatórios de Jorge Avilez ficam claras sua antipatia por José Joaquim da Rocha e sua preocupação com o que acontecia em sua casa. Sobre a ação panfletária e de recolher assinaturas junto à população da corte, o general afirmava que "todo esse negócio era manejado pelo insigne rábula Rocha" (PARTICIPAÇÃO E DOCUMENTOS 1822, p. 10).

É de interesse observar que, embora valorize as ações encabeçadas por esses indivíduos, seus perfis não são idealizados ou monumentalizados. Alexandre José de Mello Moraes julga, descreve o temperamento vaidoso de José Bonifácio ou o civismo de Vasconcellos de Drummond, por exemplo. Os personagens têm vícios e virtudes e estão no centro das articulações que promoveram a Independência do Brasil.

\section{O cânone e o Instituto Histórico e Geográfico Brasileiro}

Esquecidos pela historiografia brasileira mais recente, há muitos traços biográficos e elogios fúnebres produzidos no século XIX sobre José Joaquim da Rocha.

[...] é aquele mesmo que realizou a palavra do Ipiranga: é o Fiat da Independência [...]. É a independência da nossa pátria, é o sonho do modesto Spartaco, realizado à sombra augusta, plácida e paternal da monarquia, é a independência sem lagos de sangue, sem os horrores da anarquia, sem as monstruosidades da guerra civil... (PORTO ALEGRE 1909 , p. 516).

Esse foi o tom do discurso proferido por Manuel de Araújo Porto Alegre, assistido pela deputação nomeada pelo Instituto Histórico e Geográfico Brasileiro na ocasião do funeral de seu sócio honorário, em julho de 1848. José Joaquim da Rocha é exaltado como grande patriota, como aquele que concebera e trabalhara pela Independência e cuja trajetória de vida se entrelaçava com a história do Brasil. Em seu discurso, Porto Alegre narra uma breve biografia de Rocha, mencionando seu nascimento, casamento, sua mudança para o Rio de Janeiro e detalhes de sua atuação política: "Na época da independência a casa do Capitão Mor Rocha teve a honra de possuir, durante a estada de Avilez no Castelo, uma peça de artilharia constantemente assentada e para ela apontada". Porto Alegre encerra o seu discurso da seguinte maneira:

Sejam, pois, cumpridos os seus desejos de uma maneira solene e patriótica, e receba o Conselheiro José Joaquim da Rocha esta coroa do Brasil, em nome da Pátria, em nome da História, que Ihe afeto o Instituto Histórico, que guardará sempre a mais grata recordação do seu finado sócio honorário, do benemérito José Joaquim da Rocha, que foi o primeiro motor da nossa Independência: Independência ou morte! (PORTO ALEGRE 1909, p. 517).

Os necrológios, bem como as biografias tinham a importante função de criar o panteão nacional, a coleção de homens representativos do espírito nacional, que deveriam servir de inspiração patriótica, mas também como objetos de 
imaginação da nacionalidade. ${ }^{3}$ Ao dramatizar a vida desses homens, autores como Porto Alegre tornavam a nação uma experiência possível.

A memória de Rocha é associada à Independência, e por este evento ele se destacava na história do Brasil, mas esse procedimento não é neutro, pois realiza um profundo deslocamento em relação ao modo como esses personagens experimentaram suas próprias ações. Em certo sentido, entrar para a historiografia significava harmonizar antigas disputas, silenciar bastidores incômodos, distanciar as lutas da Independência das disputas do presente.

Para o IHGB, a figura e os feitos de Rocha eram coerentes com o discurso romântico que a instituição produzia naquele momento. Na segunda metade do século XIX, o IHGB, fundado em 1838, reunia intelectuais cujos esforços estavam centrados em desvendar o processo de nascimento e formação da nacionalidade. Todos os esforços produzidos por essa instituição se voltavam para a construção de uma "memória fundadora". Nesse sentido, indivíduos que tinham testemunhado ou sido contemporâneos aos eventos fundadores da nação, como José da Silva Lisboa, José Feliciano Fernandes Pinheiro (primeiro presidente do IHGB), José Joaquim da Cunha Matos e Januário da Cunha Barboza, entre muitos outros, colaboraram com suas obras nessa empreitada. ${ }^{4} \mathrm{O}$ esforço visava consolidar um projeto político iniciado com a separação de Portugal, embora para muitos dos seus idealizadores não houvesse uma contraposição profunda entre Portugal e Brasil. A nova nação seria continuadora de uma tarefa civilizadora que a colonização portuguesa teria iniciado: "Nação, Estado e Coroa 90 aparecem enquanto uma unidade no interior da discussão historiográfica relativa ao problema nacional" (GUIMARÃES 1988, p. 6).

Essa será sempre a tônica das biografias produzidas ao longo do século XIX. Para aqueles que escreveriam a história do Brasil, comprometidos com um projeto de construção de uma nação, o movimento feito por José Joaquim da Rocha, sua ascensão política, exílio e esquecimento se encaixavam perfeitamente no modelo do herói que servia de exemplo nacional, incluindo as insinuações providencialistas que sutilmente procuravam naturalizar a Independência como um evento inevitável, portador de um sentido mais profundo e, portanto, capaz de orientar quanto ao futuro.

Em tais biografias, contidas, por exemplo, no Anno Biographico de Joaquim Manoel de Macedo, ${ }^{5}$ destacam as qualidades intelectuais e o caráter dos políticos contemporâneos.

Ligue-se à memória do grandioso dia 9 de janeiro de 1822 o nome do modesto, mui preclaro e benemérito patriota o capitã-mor José Joaquim da Rocha que foi senão o principal ao menos o mais ativo e decidido conspirador da majestosa e elétrica revolução abraçada então pelo príncipe regente nove meses depois D. Pedro I, imperador do Brasil independente (MACEDO 1873, p. 40).

${ }^{3}$ Sobre o assunto, ver Oliveira (2015).

${ }^{4}$ Sobre o assunto, ver a obra de Guimarães (2011).

5 Mattos (2000) e Bosisio (2007) escreveram sobre o citado Manuel de Macedo. 
É interessante observar que, mesmo nas biografias produzidas pelo IHGB, Rocha seria o grande conspirador, com suas proclamações "pregadas nas esquinas das ruas da cidade" convocando o povo a se pronunciar em favor da Independência e do Príncipe. Ele teria sido o grande articulador do Fico, "pregando nas esquinas das ruas anúncios e convites, indicando as casas, onde se podia assinar aquele documento patriótico" (uma representação para a permanência do Príncipe no Brasil). Nestas narrativas, o sentido dado às ações de da Rocha, por fim, era basicamente o de criar as condições para que o Imperador Dom Pedro, na condição de herdeiro da casa de Bragança, fizesse a Independência.

A Galeria dos Brasileiros Ilustres, de Sébastien Auguste Sisson, é mais um exemplo do interesse social e editorial pelas biografias, que emergia junto com o crescente interesse pela História. Naquele momento, o IHGB não era o único local de produção de biografias: o desejo por História parecia penetrar diversas camadas da sociedade. Saber a história nacional ia se tornando um elemento de distinção social importante. No caso de Sisson, a maior preocupação era a produção de um "panteon" dos contemporâneos. Parece-nos que a tentativa de demonstrar as virtudes e o "material humano" de que o Brasil dispunha talvez fosse a mais importante missão desse panteão e das biografias produzidas no IHGB. Era ao mesmo tempo uma prova da civilização do país, o resultado incontestável que deveria ser guardado como um tesouro e continuamente exibido. Com tão virtuosos patriotas seria possível erguer aqui uma nação civilizada e moderna, sob a forma de uma monarquia constitucional, na qual as qualidades dos cidadãos eram fundamentais para a celebração do pacto político entre o monarca e a sociedade.

\section{José da Silva Lisboa, Francisco Adolfo de Varnhagen e a história do Estado}

$\mathrm{Na}$ introdução da História dos Principais Sucessos do Império do Brasil, José da Silva Lisboa, o Visconde de Cairu, explica que a obra surgiu de uma ordem do Imperador Pedro I, quem solicitara que o autor redigisse a "História dos Sucessos do Brasil, dignos de memória, particularmente desde o dia 26 de fevereiro de 1821" (LISBOA 1829). "É nessa tradição, de uma história da civilização; mais do que das guerras e conflitos; que Cairu pretende inserir a sua história, não na grande tradição clássica da história política, mas no novo regime de uma história da civilização" (ARAUJO 2010, p. 78).

Em artigo sobre Cairu e a emergência de uma consciência historiográfica no Brasil, Valdei Araujo dedica uma seção aos historiadores da Independência do Brasil. Conforme o autor, assim como acontece com a obra de Southey,

Cairu defenderá a atuação de Pedro I como decisiva para a Independência sem revolução, garantindo assim a continuidade do processo civilizatório aberto em 1808. Os acontecimentos mais recentes, principalmente o fechamento da Assembleia Constituinte e a outorga da Carta, serão testes fundamentais para a consistência da imagem de Pedro I como um monarca polido e comercial (ARAUJO 2010, p. 80). 
Oferecendo uma interpretação pelo viés político, Lúcia Neves (2007) classifica Cairu como pertencente a um grupo liberal moderado. Dessa forma, ele recusaria os extremos da revolução, mas defenderia um processo de reforma organizado em torno da ideia de regeneração. Para a escrita de uma história da Independência sem revolução, a memória do envolvimento da sociedade civil no processo precisava ser suprimida. Cairu valoriza Pedro I pela manutenção da integridade do território, critica a política das cortes, que dificultaria a unidade política, e oscila entre uma visão providencialista sobre a História e a valorização da ação do indivíduo, no caso, D. Pedro I, como representante do Estado monárquico.

Em um contexto de desagregação e formação de diversas repúblicas na América espanhola, a preocupação de Silva Lisboa era a de valorizar a unidade do império e o papel de D. Pedro no processo. A tarefa de uma "Historia Geral do Brasil" era defender o modelo civilizacional representado pelo império na forma de uma monarquia constitucional, e as obras de História como a de Cairu serviriam para educar o público, civilizar os costumes de maneira a preparar as condições para o desenvolvimento daquela sociedade: "Por isso, não se pode separar o Cairu historiador, do moralista e panfletista ou do pensador da economia, todas essas facetas eram competências necessárias ao homem de estado ilustrado em uma sociedade polida e comercial" (ARAUJO 2010, p. 85).

No livro de Cairu, José Joaquim da Rocha aparece apenas em pequenas passagens. A obra é dedicada a D. Pedro, e fica evidente nela que o Imperador estaria no centro do processo de independência.

Em casa do advogado José Joaquim da Rocha se depositou e franqueou este requerimento com a maior publicidade; e logo que houve notícia disto, grande número de pessoas sem a menor solicitação, e na mais pura espontaneidade, foram ali assinar, tendo a data de 29 de Dezembro de 1821 (LISBOA 1829, p. 10).

O citado requerimento era o "Manifesto do Rio de Janeiro" pela permanência de sua Alteza Real no Brasil. Em outras narrativas, a produção do Manifesto teria sido atitude fundamental de apoio ao monarca indeciso e ainda relutante em assumir posições políticas que iam contra os interesses das cortes ou das ordens de D. João VI. É interessante notar que, na interpretação de Silva Lisboa, muitas pessoas, "espontaneamente" e "sem a menor solicitação", teriam ido à casa do advogado assinar o documento. Dessa perspectiva, o papel do "famoso rábula Rocha" no processo nada mais seria que o de uma "formiga" construindo anonimamente -e talvez até mesmo inconscientemente- a estrutura de um processo guiado pelas mãos da providência através do futuro grande monarca do poderoso império do Brasil.

O trabalho de José da Silva Lisboa seria desqualificado por Varnhagen nos anos 70 do século XIX e no século XX por historiadores como José Honório Rodrigues, por seu caráter de "encomenda" ou por estar a serviço de D. Pedro I. Varnhagen, que também escreveria importante obra sobre a Independência do Brasil, valorizava na produção de seu trabalho a pesquisa 
documental, produzindo, sem dúvida, um dos mais influentes relatos do processo independentista, uma visão que repercute ainda hoje. Seu trabalho foi bem-sucedido na construção de uma determinada memória do Estado imperial brasileiro e, como veremos adiante, seria referência para a maioria das "histórias" produzidas desde então. Além da pesquisa documental, Varnhagen se utiliza de depoimentos de contemporâneos da Independência. Em 1841, quando da sua vinda à capital do império para requerer a nacionalidade brasileira, frequentou as sessões do IHGB, onde se tornou próximo de Januário da Cunha Barbosa e conviveu com outros notáveis do movimento da Independência, entre os quais coletou depoimentos sobre episódios que, mais tarde, utilizou na História da Independência do Brasil, antecipando-se, por assim dizer, ao que futuramente seriam consideradas práticas de história oral. Entre outros vultos, Varnhagen reporta-se aos diálogos que manteve com os marqueses de Paranaguá (Francisco Vilela Barbosa, 1769-1846), de Valença (José Bernardino de Portugal e Castro, 1780-1840), de Resende (Antônio Teles da Silva Caminha e Meneses, 1790-1875), de Monte Alegre (José da Costa Carvalho, 1796-1860) e de Sapucaí (Cândido José de Araujo Viana, 1793-1875), e também com o Senador Vergueiro, o Brigadeiro Rafael Tobias de Aguiar, além de mencionar o seu confrade no IHGB, Januário da Cunha Barbosa (GUIMARÃES 2011).

A História da Independência de Varnhagen foi concluída em 1875, mas publicada somente em 1916. Nela, o historiador inicia sua narrativa no ano de 1808 , mas dedica apenas dois parágrafos em uma obra de quase 400 páginas à chegada da família real ao Brasil e ao evento que ficou conhecido como a abertura dos portos. Na interpretação de alguns pesquisadores, esses fatos seriam os dois primeiros eventos que Varnhagen citaria como os primórdios da Independência do Brasil. Já nós acreditamos que não é a trama da Independência de Varnhagen que começa a ser traçada naquele momento, mas a da construção do império do Brasil dentro de sua grandeza territorial, ou seja, a da união das províncias em torno da política bragantina. Varnhagen relembra o ano de 1815, quando "foi toda a região, do Amazonas ao Prata, elevada à categoria de Reino [...]". Esse fato "veio a ser o segundo passo dado para formar das capitanias dos dois antigos Estados uma só nação. Assim, em meados de 1820, era já toda esta região a sede de um Império maior que o dos romanos" (VARNHAGEN [19--?], p. 20). Assim, a Independência do Brasil para Varnhagen é apenas um evento dentro da história do império do Brasil.

A chegada da corte e a abertura dos portos seriam demonstrações da importância da presença da família real na união do território e sua grandeza. O historiador compreende que a inversão dos papéis incomodava a antiga metrópole. No parágrafo dedicado a relatar esse dado histórico, vemos mais uma exaltação às qualidades do "bom rei, que se encontrava mais feliz na sua quinta de São Cristóvão", do que elementos relevantes para a compreensão da trama da Independência. O rei seria muito querido pelo povo da nova capital, "onde desde que nela desembarcara, vira sua autoridade real mais acatada do que nunca antes havia sido" (VARNHAGEN [19--?], p.17). 
Já os acontecimentos de 1817 em Pernambuco são descritos como uma "primeira conspiração", obra da maçonaria portuguesa que desejava aclamar o "rei constitucional" e "atraí-lo" para Portugal. A saída de D. João do Brasil seria obra de conspiradores como o liberal Gomes Freire de Andrade. Na sua História Geral do Brasil afirma que preferiria "cobrir a Revolução de 1817 com o véu do esquecimento" (VARNHAGEN 1978 [1854-857], p. 149 apud MOREL 2007, p. 201).

É interessante perceber como as obras de Varnhagen e Mello Moraes, escritas no mesmo período, constroem a trama da formação da nação a partir de perspectivas tão distintas, que determinam leituras diferentes tanto da ação das sociedades secretas ou dos protagonistas dos processos políticos narrados, quanto a denominação de eventos como o acontecido em Pernambuco em 1817, que para Moraes seria uma revolução patriótica e, para Varnhagen, uma "conspiração" contra o monarca. Ao longo da sua obra, resultam evidentes a postura favorável de Varnhagen à monarquia constitucional com tons reformistas e sua crítica a posições mais liberais, de um constitucionalismo/ liberalismo exaltado.

Varnhagen começa a contar a história da Independência do Brasil a partir da Revolução Constitucional no Porto, numa cronologia muito parecida com a resultante da interpretação de contemporâneos como Cairu, preocupados em legitimar a Independência no horizonte político e nas linguagens legitimistas póscongresso de Viena. Para eles, a Independência é uma ação contrarrevolucionária e legitimista.

O quotidiano político do processo de Independência é reconstruído com muita riqueza de fontes e relatos. Os protagonistas da Independência brasileira são o herdeiro da dinastia de Bragança e seu projeto de uma monarquia constitucional e preservação da dinastia no Brasil. Diante disso, percebemos que personagens como José Joaquim da Rocha aparecem nesta obra como colaboradores desse projeto, coadjuvantes em uma peça em que os protagonistas eram a dinastia, o rei e o jovem Príncipe. Embora o futuro conselheiro de D. Pedro II seja citado em diversos momentos, sua importância é minimizada.

Também o desejo pela Constituição e as ideias liberais de constitucionalismo eram objetos de manipulação, ferramentas nas mãos do grande monarca, que com sabedoria conduziria esse instrumento de maneira a produzir com ele os melhores resultados para o Brasil. A Constituição poderia ter sido tranquilamente substituída por uma reforma, a revolução constitucional e a Independência no Brasil poderiam ter sido feitas de outra forma se seguissem o projeto reformista encabeçado pela casa de Bragança.

Observemos como Varnhagem interpretava os mesmos episódios narrados por de Mello Morais. Por volta de $1^{0}$ de janeiro de 1822, quando se iniciam as articulações para a permanência do Príncipe no Brasil, Varnhagen cita o Manifesto do Rio de Janeiro:

Em 30 escrevia ainda a el-rei seu pai que seguia a mesma situação, com a diferença de estarem ainda mais arraigadas as opiniões; protestava de 
novo que "por falta de diligências suas, não deixariam de ser cumpridas as soberanas ordens". Não tardou a ter conhecimento do teor do manifesto do povo do Rio de Janeiro, datado do dia 29, e que veio a reunir mais de 8.000 assinaturas (VARNHAGEN [19--?], p. 92).

Conforme a obra de de Mello Moraes, essas assinaturas teriam sido recolhidas por José Joaquim da Rocha e seus filhos, que estiveram à frente do processo, em ação militante nas ruas. Na narrativa de Varnhagen, as pessoas à frente da redação do manifesto não possuíam nomes. Na versão deste autor, D. Pedro passaria a receber manifestos e ofícios da Junta de São Paulo e de outras províncias, bem como as delegações de representantes eleitos às cortes. Hesitante, o Príncipe teria ouvido os conselhos de seu ministro Tomás Antônio Vila Nova Portugal, antigo ministro de D. João. Para salvar a monarquia bragantina e os reinos de Portugal e do Brasil, deveria ficar.

Os protagonistas dessa História da Independência do Brasil não poderiam ser outros, senão os membros da monarquia portuguesa e figuras "oficiais" do Estado. Essa interpretação explica o caso de José Clemente Pereira, que como presidente do Senado, de quem Varnhagen cita várias falas e inclusive seu discurso oficial pedindo ao Príncipe que ficasse no Brasil. A articulação das ruas, da sociedade civil, não tem espaço na obra de Varnhagen, ou ocupa um lugar tendencialmente negativo.

Parece ser esse também o "problema" de Varnhagen com aquele que, ainda hoje, é reconhecido como o "patriarca" da Independência. Passada a crise política que aconteceu na sequência do Fico, em que tropas se colocaram em armas exigindo o retorno do Príncipe a Portugal, deu-se a entrada de Bonifácio ao Ministério, que Varnhagen descreve como positiva por ter dado mais unidade ao governo do Príncipe. Destaca seu grande saber, "o gênio intrépido, o seu caráter pertinaz, que quase chegava a raiar em defeito, contribuíram a fixar a volubilidade do príncipe" (VARNHAGEN [19--?], p. 102). Porém, o historiador aponta uma ressalva em relação a Bonifácio: "Cegava-o por vezes, como a seus irmãos, o muito orgulho, a falta de prudência e o excesso da ambição" (VARNHAGEN [19--?], p. 102), defeitos compensados, conforme Varnhagen, pela boa instrução. José Bonifácio é considerado por certa memória-historiografia o patriarca da Independência do Brasil. No entanto, Varnhagen, não somente na História da Independência, mas também na sua História Geral, de 1857, tende a minimizar a importância do "patriarca" e a destacar características de sua personalidade "falastrona" e ambiciosa.

Transparece na leitura de sua obra um incômodo com a força e protagonismo de Bonifácio em determinados momentos decisivos em que valoriza a ação do Príncipe D. Pedro, a quem Varnhagen também critica por estar sob forte influência do Andrada:

Longe de o recriminarmos por isso, cremos que parte da culpa tinha o governo, que, só por que ele havia estado muitos anos estudando, principalmente na Alemanha, julgava que em tudo o devia envolver. O resultado foi que José Bonifácio, que de tudo entendia, que nas congregações em Coimbra muito influía [...] tomava parte nas discussões, 
ainda que assuntos em que o julgavam menos versado... (VARNHAGEN, apud CEZAR 2005, p. 14).

O debate sobre o papel atribuído a José Bonifácio na obra de Varnhagen é antigo, e não pretendemos adentrar nele. Vale, no entanto, lembrar que Temístocles Cézar, em estudo sobre a imparcialidade na obra de Varnhagen, demonstra que havia problemas inclusive de ordem pessoal entre ele e José Bonifácio.

Também José Honório Rodrigues acusaria algum problema na postura de Varnhagen em relação a Bonifácio, atribuindo-o a discrepâncias de ordem política, sentimental e também teóricas. Bonifácio seria "representante da opinião 'contrarrevolucionária'"' no processo de independência (CEZAR 2005, p. 227).

Obra de defesa de D. Pedro, em detrimento de José Bonifácio na elaboração da independência, de desvalorização da guerra de independência, para que esta surja como um desenvolvimento momentâneo e não uma ruptura com o regime colonial a que teria sido levado o Brasil, caso Bonifácio não tivesse sido expulso do processo histórico. O autor sente que sua responsabilidade não é só com o Brasil, mas com Portugal (RODRIGUES apud CEZAR 2005, p. 221).

Ainda na análise de Cezar da leitura de Honório Rodrigues, "Varnhagen jamais aceitaria que a História não fosse fruto apenas de personalidades mais ou menos cultas" (CEZAR 2005, p. 227).

A história da Independência não deveria estar concentrada apenas em Bonifácio. Em nossa leitura, a figura de José Bonifácio e a força com que permaneceu na história da Independência do Brasil comprometeriam em dois aspectos as convicções de Varnhagen sobre essa história. Em primeiro lugar, sua autoridade sobre D. Pedro. Como em vários trechos o próprio Varnhagen destaca, José Bonifácio tivera grande influência sobre o ainda jovem e despreparado Príncipe, que, num primeiro momento, estivera sob a tutela do pai e, depois, seguiria sob a de Bonifácio. Em segundo lugar, a história da monarquia portuguesa, para Varnhagen, não seria a história de homens, seria a história do Brasil e sua formação como Estado e nação, que, conforme o autor, prevaleceria sobre a história dos indivíduos.

Essa história vazia de indivíduos produzida por Varnhagen explica, por exemplo, por que o autor considera "notável" documento o ofício enviado à Junta de governo de Minas Gerais declarando apoio ao Príncipe. Citando trechos desse documento, valorizava a fala de que as cortes pretendiam reduzir as províncias do Brasil à condição de colônia. Valorizava a imagem do pacto de uma "sagrada federação", criticava as medidas inconstitucionais das cortes e exaltava a ideia de um laço unindo toda a monarquia. Varnhagen não menciona o autor do documento, José Joaquim da Rocha. Para o Visconde de Porto Seguro, o documento não tinha sido redigido por um indivíduo; a sua força residiria exclusivamente na própria suaoficialidade.

O protagonismo de José Joaquim da Rocha é destacado em muitas narrativas, especialmente na de Mello Moraes, nas exaltações e disputas que 
se deram na sequência do dia 9 de janeiro. Depois da declaração de D. Pedro de que ficaria no Brasil, vários regimentos se colocaram em armas "declarando em altas vozes que obrigariam o príncipe a embarcar-se naquela mesma noite".

Observemos como Varnhagen narra esse mesmo momento, colocando no centro os eventos e como a monarquia lidou com eles:

Seja como for, é certo que nessa mesma noite começou, por seu turno, a reunir-se no Campo de Sant'Ana toda a tropa de linha e miliciana do país, incluindo os regimentos dos Henriques e de Pardos, que então havia, e, além da mesma tropa, um sem-número de cidadãos de todas as classes, cada qual armado como pôde, entrando neste número muitos eclesiásticos e até frades. E cumpre dizer que muitos dos principais chefes, que aí se encontraram, eram até filhos de Portugal, começando pelo Ajudante-General Oliveira Álvares, que tomou a princípio o comando (VARNHAGEN [19--?], p. 99).

É interessante observar como os nomes que se destacam são os dos agentes e servidores da monarquia, que agiram prestando serviço ao Príncipe e por isso são recompensados. Percebemos, ainda, como Varnhagen, talvez preocupado em criar as condições da memória da Independência, tenta criar a ideia de um diálogo com a sociedade ou de apoio até mesmo do baixo estrato, "cidadãos de todas as classes", que era evitado por certa historiografia ou muitas vezes usado para deslegitimar determinados movimentos.

Outro momento decisivo para a consolidação da regência de Dom Pedro foi a viagem à província de Minas Gerais em março de 1822, que também contou com a iniciativa e colaboração de indivíduos como Rocha e seu grupo. Naquele contexto de sobreposição e confusão dos poderes que se desenrolara com a chegada de notícias sobre a Revolução do Porto, a província não se subordinara nem às cortes, nem ao governo do Rio de Janeiro; pelo contrário, tendera a autonomizar-se. Varnhagen condena em sua narrativa os "absurdos" da insubordinação da Junta de Governo de Minas Gerais, narrando assim a forma como o Príncipe lidou com a situação: "Foi rápida a jornada e quase se reduziu a uma carreira triunfal. No dia $1^{\circ}$ de abril chegou a Barbacena [...], Ihe suplicou que estabelecesse na província um governo provisório e constitucional, que prevenisse o espírito de divisão e a anarquia que ameaçava rebentar" (VARNHAGEN [19--?], p. 112). Em meio a festejos e arcos do triunfo, o Príncipe regente teria sido recebido nas vilas da província com muito entusiasmo, e membros do governo provisório teriam vindo beijar-lhe a mão.

Analisando fontes como a correspondência trocada entre diversos atores no período, sabemos que a recepção de D. Pedro em Minas Gerais foi articulada muito antes por emissários como Paulo Barbosa, que tinha saído do Clube da Rua da Ajuda e percorrera, em dezembro, fazendo negociações pelas vilas da província, todo o trajeto que o Príncipe viria a fazer em abril. Antes ainda, José Joaquim da Rocha travara correspondência com as câmaras das vilas do interior de Minas Gerais, preparando sua chegada. O relato de Varnhagen obscurece toda essa articulação, contribuindo para consolidar uma memória de um adesismo imediato por parte das autoridades do interior de Minas Gerais, que teriam sido seduzidas pela forte presença e impressão produzida pelo futuro Imperador do Brasil. 


\section{Conclusões}

Existem muitas histórias sobre a Independência do Brasil. Talvez a versão mais forte dentre tantas seja aquela que valoriza a ideia de um processo de ruptura política conduzida pela monarquia e pelas elites burocráticas do Estado, afastando a ideia de uma revolução com participação popular e fazendo prevalecer elementos de continuidade histórica, mais do que rupturas, e apresentando como chave orientadora dessa experiência uma transição quase que automática do reformismo para o constitucionalismo. Essa é, como vimos, a interpretação de historiadores como José da Silva Lisboa e Francisco Adolfo de Varnhagen, fortemente influenciada pela retórica da contrarrevolução.

Seguindo o cânone historiográfico, esses autores ajudaram a construir uma memória do processo de Independência que seria também uma memória do Estado e da monarquia, numa versão que suprime parte importante da experiência do constitucionalismo e da sociedade civil naquele contexto. Ainda hoje, no plano do que podemos chamar de cultura de história, que poderia se aproximar de uma memória histórica, personagens como José Joaquim da Rocha, Antônio Menezes Vasconcellos de Drummond e outros são absolutamente desconhecidos no processo, bem como as ações e manifestações populares como a revolta na Praça do Comércio. ${ }^{6}$

De acordo com pesquisa coordenada por João Paulo Pimenta, ${ }^{7}$ a maior parte do público não especializado que se interessa pela história do Brasil não considera que a Independência do Brasil seja um evento importante, considerando que o "Descobrimento" ou personagens como "Tiradentes" sejam, eles sim, verdadeiramente fundadores. Marco Morel (2007, p. 196) chama a atenção para a forma como é feita essa operação:

É instigante verificar que episódios concebidos pelos contemporâneos como revoluções foram rebatizados, posteriormente, com nomes curiosos como Cabanagem ou Balaiada [...] Hoje em dia, no terreno da memória histórica e, mesmo, da iconografia, quando avaliamos nosso conhecimento sobre as revoltas do período regencial, podemos nos dar conta de que desconhecemos os rostos e as feições do escravo Cosme Bento das Chagas e do vaqueiro Raimundo Gomes, que se destacaram na Balaiada; dos irmãos Francisco e Antônio Vinagre, da Cabanagem. Indivíduos que controlaram largas faixas territoriais e destituíram governos locais. Ignoramos a aparência das dezenas de chefes de bandos armados que integraram estes dois movimentos e tantos outros, como a Cabanada (Pernambuco e Alagoas) e a Farroupilha (Rio Grande do Sul e Santa Catariana); do médico Francisco Sabino Vieira, da Sabinada, de Pacífico Licutan, Manoel Calafate e Elesbão do Carmo, do levante dos Malês; do escravo, tropeiro considerado "rei Africano", Ventura da Mina, da Revolta das Carrancas (Minas Gerais). Como somos levados a visualizar (ou não ver), gravar em nossas memórias, as rebeliões das Regências e seus protagonistas?

\footnotetext{
${ }^{6}$ Quando, em 22 de abril de 1821, as tropas portuguesas cercaram o edifício no qual acontecia uma reunião da Junta eleitoral, várias pessoas foram mortas e outras tantas foram feridas.

7 Os resultados da pesquisa feita a partir de entrevistas com um público amplo e não especializado nas ruas da cidade de São Paulo foram apresentados em: Pimenta et al. (2014).
} 
O mesmo acontece com personagens como José Joaquim da Rocha, conhecido no período como o "célebre rábula, cabeça do movimento", ligado à ação nas ruas e que aparece nas obras canônicas como o "Conselheiro Rocha", referência ao título de Conselho do Estado que recebeu posteriormente, embora jamais tenha feito parte do Conselho do Imperador D. Pedro II.

Em suas obras, Varnhagen e Silva Lisboa precisavam construir uma narrativa que reunisse homens, forças políticas, acontecimentos e circunstâncias de um processo em torno da monarquia. Para tanto, foi necessário excluir as ruas e a sociedade civil da escrita da história da Independência do Brasil, o que implicava excluir parte importante da experiência constitucional e do constitucionalismo.

O conteúdo liberal e constitucional do movimento aparece apenas como uma retórica que escondia a ideia de que, por fim, as cortes desejavam "recolonizar" o Brasil. Essa ideia de que, não fosse o movimento revolucionário do Porto em 1820, a Independência do Brasil aconteceria de maneira natural, fruto de um amadurecimento das relações com Portugal e do coroamento de um projeto civilizacional sabiamente conduzido pela monarquia portuguesa, passa a ser contestada e repensada com obras escritas a partir do século XX.

\section{Referências bibliográficas}

ARAUJO, Valdei Lopes de. Cairu E a Emergência Da Consciência Historiográfica No Brasil (1808-1830). In: GONTIJO et al. Estudos de Historiografia Brasileira. Rio de Janeiro: FGV, 2010, p. 75-92.

. Historiografia, nação e os regimes de autonomia na vida letrada no

Império do Brasil. Varia historia, v. 31, n. 56, p. 365-400, 2015.

BOSISIO, Rafael de Almeida Daltro. Entre o escritor e o historiador: a História

Do Brasil imperial na pena de Joaquim Manuel de Macedo. Dissertação (Mestrado em História) - Programa de Pós-Graduação em História, Universidade Federal do Rio de Janeiro, Rio de Janeiro, 2007.

CEZAR, Temístocles. Em nome do pai, mas não do patriarca: ensaio sobre os limites da imparcialidade na obra de Varnhagen. História, v. 24, n. 2, p. 207-240, 2005.

GUIMARÃES, Lúcia M. P. G. Debaixo da imediata proteção imperial. Instituto Histórico e Geográfico Brasileiro. 1838-1889. São Paulo: Annablume, 2011.

Debaixo da imediata proteção de Sua Majestade Imperial: o Instituto Histórico e Geográfico Brasileiro (1838-1889). Revista do Instituto Histórico Geográfico Brasileiro, ano 156, n. 388, p. 459-613, 1995.

. Francisco Adolfo de Varnhagen: "História geral do Brasil". In: MOTA, Lourenço Dantas (Org.). Introdução ao Brasil. Um banquete no trópico.

3. ed. São Paulo: Ed. SENAC, 2011, p. 75-96. v. 2.

GUIMARÃES, Manoel Luis Salgado. Nação e Civilização nos Trópicos: O Instituto Histórico e Geográfico Brasileiro e o projeto de uma História Nacional.

Revista Estudos Históricos, n. 1, p. 5-27, 1988. 
HABERMAS, Jürgen. Mudança estrutural da esfera pública: investigações quanto a uma categoria da sociedade burguesa. Tradução de Flávio R. Kothe. Rio de Janeiro: Tempo Brasileiro, 1984.

JUNIOR, Paulo Alves. O pensamento radical de José Honório Rodrigues: a Conciliação na História do Brasil. Encontro Regional de História, XIX: Poder, Violência e Exclusão. Anais... São Paulo: ANPUH, 08 a 12 set. 2008. Disponível em: <http://www.anpuhsp.org.br/sp/downloads/CD\%20XIX/ PDF/Autores\%20e\%20Artigos/Paulo\%20Alves\%20Junior.pdf>. Acesso em: 25 abr. 2016.

LISBOA, Jose da Silva. História dos principais sucessos políticos do Brasil. Rio de Janeiro: Tipografia nacional, 1829.

MACEDO, Joaquim Manuel de. Anno Biographico Brazileiro. Rio de Janeiro: Typographia e Lithographia do Imperial Instituto Artistico, 1876. Primeiro vol. de 3. Disponível em: <http://www.brasiliana.usp. $\mathrm{br} /$ ?filtertype $=\% 2 \mathrm{~A} \&$ filter $=\% 22$ ano+biogr\%C3\%A1fico\%22+\&submit_ search-filter-controls_add=Buscar>. Acesso em: abr. 2016

MALEVAL, Isadora Tavares. 2015. Entre a "arca do sigilo" e o "tribunal da posteridade": o (não) lugar do presente nas produções do Instituto Histórico Geográfico Brasileiro (1838-1889). Tese (Doutorado em História) - Universidade do Estado do Rio de Janeiro, Rio de Janeiro, 2015.

MATTOS, Selma Rinaldi de. O Brasil em lições: a História como disciplina escolar em Joaquim Manoel de Macedo. Rio de Janeiro: Access, 2000.

MORAES, Alexandre José de Mello. História do Brasil-Reino e Brasil-Império compreendendo: a história circunstanciada dos ministérios, pela ordem cronológica dos gabinetes ministeriais, seus programas, revoluções políticas que se deram, e cores com que apareceram, desde o dia 10 março de 1808 até 1871. Rio de Janeiro: Typ. de Pinheiro \& c., 1871-73. Disponível em: <http://www2.senado.leg.br/bdsf/item/id/182897>. Acesso em: maio 2014.

MOREL, Marco. Nação e revolução: o rubro veio historiográfico no Brasil na primeira metade do século XIX. In: CHAVES, Cláudia Maria das Graças; SILVEIRA, Marco Antonio (Org.). Território, conflito e identidade. Belo Horizonte: Argumentum, 2007.

NEVES, Lúcia Maria Bastos P. das. Revolução: em busca de um conceito no império luso-brasileiro (1789-1822). FERES Jr., João; JASMIN, Marcelo (Org.). História dos conceitos: diálogos transatlânticos. Rio de Janeiro: Ed. PUC-Rio/ Loyola/IUPERJ, 2007, p. 129-140.

OLIVEIRA, Maria da Glória de. Sobre a exemplaridade das vidas ilustres no Brasil oitocentista. Anos 90, n. 22 (42), p 273-294, 2015.

PARTICIPAÇÃO E DOCUMENTOS dirigidos ao Governo pelo General Comandante da Tropa Expedicionária, que existia na província do Rio de Janeiro, chegando a Lisboa: e remetidos pelo Governo às Cortes Gerais, Extraordinárias e 
Constituintes da Nação Portuguesa. Lisboa: Imprensa Nacional, 1822. (Edição disponível na Biblioteca Nacional de Lisboa)

PIMENTA, João Paulo et al. A independência e uma cultura de história no Brasil.

Revista Almanack, n. 8, p. 5-36, 2014.

. A independência do Brasil como uma revolução: história e atualidade de um tema clássico. História da Historiografia, n. 3, p. 53-82, 2009.

PORTO ALEGRE, Manuel de Araujo. O Conselheiro José Joaquim da Rocha. Revista do Arquivo Público Mineiro, ano 14, p. 515-517, 1909 [1848].

SANTOS, Pedro Afonso Cristóvão dos. Compilação e plágio: Abreu e Lima e Melo Morais lidos no Instituto Histórico e Geográfico Brasileiro. Revista de História da Historiografia, n. 13, p. 45-62, 2013.

SOUZA, Francisco Gouvea de. Proclamação e Revolta: recepções da República pelos sócios do IHGB e a vida na cidade (1880-1900). Tese (Doutorado em História) - Pontifícia Universidade Católica do Rio de Janeiro, Rio de Janeiro, 2012.

VARNHAGEN, Francisco Adolfo de. História da independência do Brasil até o seu reconhecimento pela antiga metrópole, compreendendo, separadamente, a dos sucessos ocorridos em algumas províncias até essa data. 4. ed. São Paulo: Melhoramentos [19--?]. 